\title{
A study to develop motor fitness reference values of secondary school children in Sri Lanka
}

\author{
K.S.H.M.V.W.W. Senevirathne \\ Department of Education, Faculty of Arts, University of Peradeniya, Sri Lanka \\ DOI: https://dx.doi.org/10.47772/IJRISS.2021.5331
}

\begin{abstract}
There is a dearth of reference values of physical fitness including motor fitness for secondary school children in Sri Lanka. The objectives of this study are to contribute to the available knowledge concerning the assessment agility $(4 \times 10 \mathrm{~m}$ shuttle run), identifying sex and age-related norms of agility of the secondary school children in Sri Lanka. A quantitative approach was used in this study. Physical fitness assessments were implemented to measure $4 \times 10 \mathrm{~m}$ shuttle run of 1229 students (638 boys and 591 girls) which was a randomly selected sample in the Kandy District. All the data were computed and analyzed to formulate test norms as percentile values, stratified by chronological age groups separately for boys and girls. All the calculations were performed using SPSS vs. 17 for windows. revealed that $P 5$ of the $4 \times 10 \mathrm{~m}$ shuttle run time of age 17 boys were very low comparing to other younger age groups. But at the end of the higher performance levels such as P75, P90 and P95, age 17 boys are performed better than their younger counterparts. This is an unusual pattern. The performance of girls of $4 \times 10 \mathrm{~m}$ shuttle run which is indicate that there are clear differences between age groups. Age 11 girls perform at a low level of agility as the normal and it is increased up to age 17 category gradually. The lowest $P 5$ of boy's $4 \times 10 \mathrm{~m}$ shuttle run test performance is 14 seconds and the highest $P 5$ is 13.25 seconds. Meanwhile, lowest P95 of boy's $4 \times 10 \mathrm{~m}$ shuttle run test performance is 11.7 sec. and the highest $\mathrm{P95}$ is $9.7 \mathrm{sec}$. According to the graphs the lowest P5 of girls' $4 \times 10 \mathrm{~m}$ shuttle run test performance is 15.7 sec. and the highest $P 5$ is $14.7 \mathrm{sec}$. Furthermore, lowest $\mathrm{P95}$ of girls' $4 \times 10 \mathrm{~m}$ shuttle run test performance is $12.3 \mathrm{sec}$. and the highest $\mathrm{P95}$ is $11.3 \mathrm{sec}$. These norms are identical for some specific population. The agility levels of Sri Lankan children (both boys and girls) are not in the range of poor range. They are slightly different with the USA and European norms. However, we cannot say agility level of Sri Lankan boys and girls are not in a satisfactory level compared to such as USA standards, because these figures are normative base values
\end{abstract}

Key words: 4x10m Shuttle Run, Reference Value

\section{INTRODUCTION}

$\mathrm{T}$ here are a lot of scientific evidences to demonstrate that physical fitness reduces the risk of morbidity and mortality from a number of chronic diseases (Biddle et al, 2004). The recognition of the importance of physical fitness for optimal health has led to an increased interest in the study of different aspects of physical fitness. The overweight and obesity prevalence among children in Sri Lanka show different ranges with provincial and gender variations; among boys and girls between 8 and 10 years this was $4.3 \%$ and $3.1 \%$ respectively and obesity prevalence among primary schoolchildren in Colombo district is $5.1 \%$ in 2008 (Thilakarathne and Wijesinghe, 2011; Wickramasinghe et al, 2004; Medical Research Institute of Sri Lanka, 2002). There were 3.8 million adolescents in Sri Lanka (2013) accounting $19 \%$ of population. Associated risk behaviors not only influence morbidity and mortality of adolescents, but also have long -lasting impact in determining future health and fitness (Danansuriya et al, 2013). Motor fitness is one of the major components of the health-related fitness.Motor fitness refers to components that are thought to improve the ability to learn and perform motor skills and include balance, coordination, agility, and speed. Many refer to this component as skill-related or performance-related fitness. The acquisition and improvement of motor skills is often a primary focus of physical education and youth sports programs, since it is assumed that this foundation provides a basis for the maintenance of active lifestyles over time (Welk \& Meredith (Eds.) (2008).

There is a dearth of reference values of physical fitness including motor fitness for secondary school children in Sri Lanka. The objectives of this study were to contribute to the available knowledge concerning the assessment $4 \times 10 \mathrm{~m}$ shuttle run and identifying sex and age-related reference values for agilityof the secondary school children in the Kandy district in Sri Lanka and to compare these values with other similar studies.

Author came across two major conceptual frameworks which were relating to physical fitness concept namely Consensus Guidelines Model (Bouchard \& Shephard (1994) for Health related physical fitness and Institute of Medicine (IOM) Model (USA). These two models comprehensively discussed the relating factors to the Health Related physical Fitness (HRPF) concept and furthermore these models describe concept of HRPF under sub themes of morphological, muscular, motor, cardio respiratory, and metabolic fitness. Before 1994 there was no consensus among the sports scientists around the World on a concept of HRPF. To fulfill this need sports scientists and physical educationists gathered at Toronto, Canada in 1994 for landmark consensus conference on physical activity, fitness, and health led to the creation of a detailed conceptual framework for health-related fitness (Bouchard \& Shephard, 1994).This model also named as a Toronto model because well reputed physical educationists and sports scientists agreed and develop this 


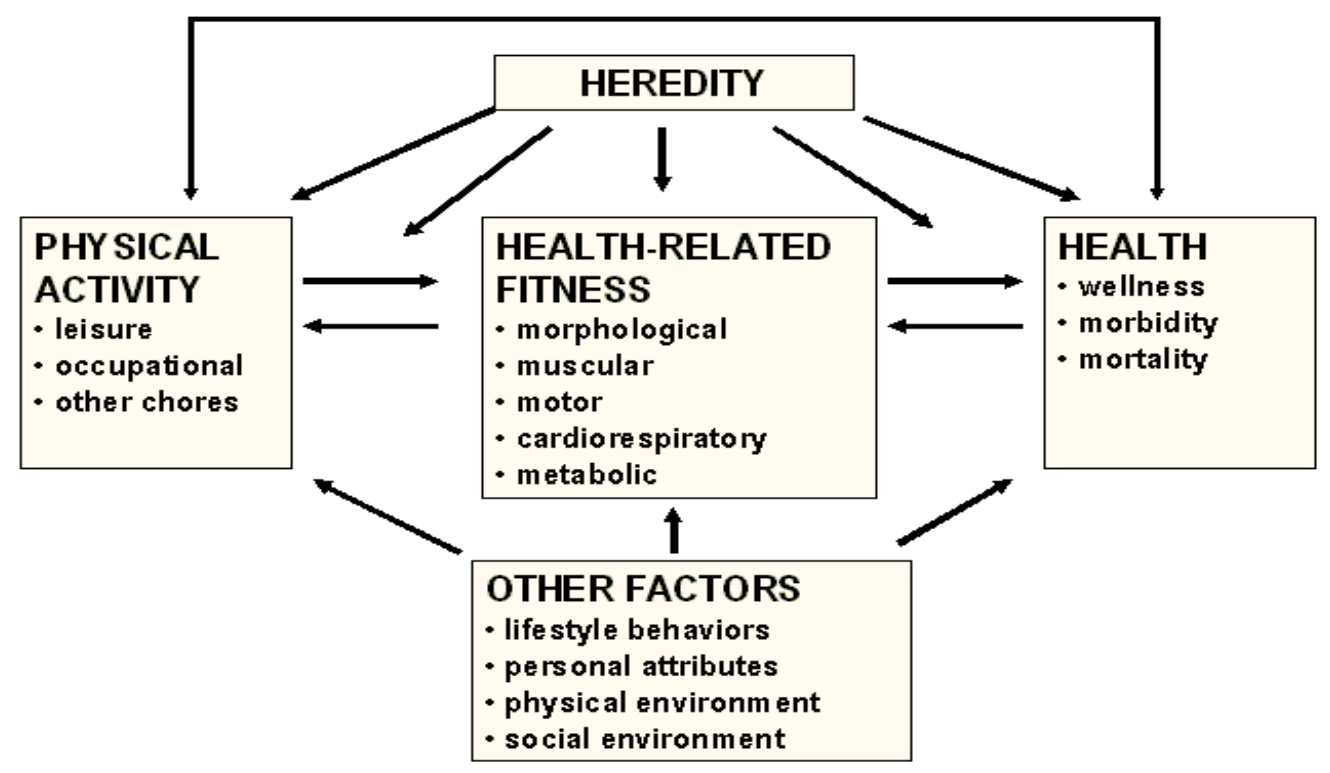

Figure 01: Consensus Guidelines Model (1994) - (Bouchard \& Shephard 1994)

The above model considers the impact of heredity on HRPF and proposes different dimensions or components of physical fitness (morphological, muscular, motor, cardio respiratory, and metabolic). The model includes different dimensions than proposed by Caspersen et al. (1985), but this is because it takes a broader approach with regard to the concept of healthrelated fitness. This model was used as a theoretical framework of this study.The model also defines five main components of health related fitness:

1. A morphological component (body mass for height, body composition, ubcutaneous fat distribution, abdominal visceral fat, bone density, flexibility);

2. A muscular component (muscular power, muscular strength, muscular endurance);

3. A motor component (agility, balance, coordination, speed of movement);

4. A cardiorespiratory component (submaximal exercise capacity, maximal aerobic power, heart functions, lung functions, blood pressure); and

5. A metabolic component (glucose tolerance, insulin sensitivity, lipid and lipoprotein metabolism, substrate oxidation characteristics) (Bouchard and Sheppard, 1994; Pate, 1988).

\section{MATERIALS AND METHODS}

A quantitative approach was used in this study. A cross sectional survey method was adopted to measure $4 \times 10 \mathrm{~m}$ shuttle run test of 1229 students (638 boys and 591 girls) which was randomly selected sample in the Kandy District. A Multi-stage sampling method was adopted to select this student sample aged between 11 years and 17 years. To ensure standardization of data collection six physical education teachers thoroughly trained as data collectors through training workshop. Well known Agility test $(4 \times 10 \mathrm{~m}$ shuttle run test)was used in this study. There are various types of agility tests such as 'Change of Direction and Acceleration Test (CODAT), Illinois Agility Run (IAR) and $4 \times 10 \mathrm{~m}$ shuttle run. In this study $4 \times 10 \mathrm{~m}$ shuttle run was used to measure children's agility. The agility test indicates an assessment on the speed of movement, agility and coordination (Ortega et al (2012). In this study $4 \times 10 \mathrm{~m}$ shuttle run was assessed on the non-slippery open ground.

Two parallel lines were drawn on the floor $10 \mathrm{~m}$ apart, for the running and turning (shuttle) test at maximum speed $(4 \times 10$ $\mathrm{m})$. In the start line there is one sponge and in the opposite line, there are two sponges. When the start is given, the child (without sponge) runs as fast as possible to the other line and returns to the starting line with the sponge, crossing both lines with both feet. The sponge is changed by the sponge in starting line.

Then goes back running as fast as possible to the opposite line and change the sponge and run back to the starting line. The tester showed the right performance. Two trials were performed and the best time was scored. The test stops when the child crosses the finishing line with one foot. The child should not slip or slide during the test. Therefore, a slip-proof floor was used.

The copies of information letters, physical activity readiness questionnaire and consent form were sent to schools for distribution to relevant parents/ guardians of students for their signatures to give the consent for their children to participate. Students that returned their completed parental consent forms with completed physical activity readiness questionnaire were 
invited to participate. The physical activity readiness questionnaire, which was administered to parents was aimed at obtaining awareness data on the levels and history of health condition of their children to make inclusion for the study . This questionnaire was adapted from revised version of the Physical Activity Readiness Questionnaire (PAR -Q and You, 1994) owned by the Canadian Society for Exercise Physiology. The result was scored in Seconds with one decimal.All the data were computed and analyzed to formulate test norms as percentile values, stratified by chronological age groups separately for boys and girls. All the calculations were performed using SPSS vs. 17 for windows.

\section{RESULTS}

Table 1 shows the normative values of $4 \times 10 \mathrm{~m}$ shuttle run test of age categoriesfrom 11 to 17 years for the Sri Lankan secondary school students, as it was done in age categories, it was classified according to sex and age expressed in percentiles from 5 to 95 .

\begin{tabular}{|c|c|c|c|c|c|c|c|c|}
\hline Age & & P5 & P10 & P25 & P50 & P75 & P90 & P95 \\
\hline $11 \mathrm{yrs}$ & Male & 13.8755 & 13.5070 & 12.9025 & 12.3300 & 11.9000 & 11.4430 & 11.2080 \\
\hline & Female & 15.2450 & 14.6900 & 14.3950 & 13.5800 & 12.7450 & 12.3600 & 12.1000 \\
\hline $12 \mathrm{yrs}$ & Male & 13.4680 & 13.1640 & 12.6100 & 11.7900 & 11.3600 & 10.9900 & 10.5760 \\
\hline & Female & 15.2360 & 14.6900 & 14.0300 & 13.4800 & 12.7500 & 12.1200 & 11.7460 \\
\hline $13 \mathrm{yrs}$ & Male & 13.6440 & 13.0600 & 12.4000 & 11.7900 & 11.3500 & 10.9100 & 10.8040 \\
\hline & Female & 15.5010 & 15.1520 & 14.1425 & 13.3450 & 12.2975 & 11.6070 & 11.3840 \\
\hline $14 \mathrm{yrs}$ & Male & 13.3190 & 12.9000 & 12.1125 & 11.5700 & 10.9925 & 10.3810 & 10.2320 \\
\hline & Female & 15.7610 & 15.2420 & 14.7500 & 13.5550 & 12.8400 & 12.1030 & 11.3840 \\
\hline $15 \mathrm{yrs}$ & Male & 13.2000 & 12.9000 & 11.7775 & 11.3300 & 10.9000 & 10.2880 & 10.1780 \\
\hline & Female & 15.6450 & 15.2740 & 14.8700 & 14.2000 & 13.2050 & 12.5100 & 11.7260 \\
\hline $16 \mathrm{yrs}$ & Male & 13.6000 & 13.3860 & 11.9575 & 11.2300 & 10.6725 & 10.2010 & 10.0805 \\
\hline & Female & 14.7940 & 14.7480 & 14.1300 & 13.5000 & 12.3800 & 11.6540 & 11.2040 \\
\hline $17 \mathrm{yrs}$ & Male & 14.0275 & 13.6600 & 12.6600 & 11.5850 & 10.4275 & 9.9600 & 9.7750 \\
\hline & Female & 14.8720 & 14.7620 & 14.0000 & 12.7800 & 12.0000 & 11.5380 & 11.1000 \\
\hline
\end{tabular}

Table 1: Normative values of $4 \times 10 \mathrm{~m}$ shuttle run test of age categoriesfrom 11 to 17 years

According to the above percentile table boys performed better than girls in agility test (4x10 m Shuttle Run) in all the age categories. It is also revealed that the performance of the $4 \times 10 \mathrm{~m}$ shuttle increased according to their physical growth pattern and not significant contradiction with growth.

Figures 2 and 3 illustrate the performance of $4 \times 10 \mathrm{~m}$ shuttle run (agility test) norms of boys and girls according to their age category.

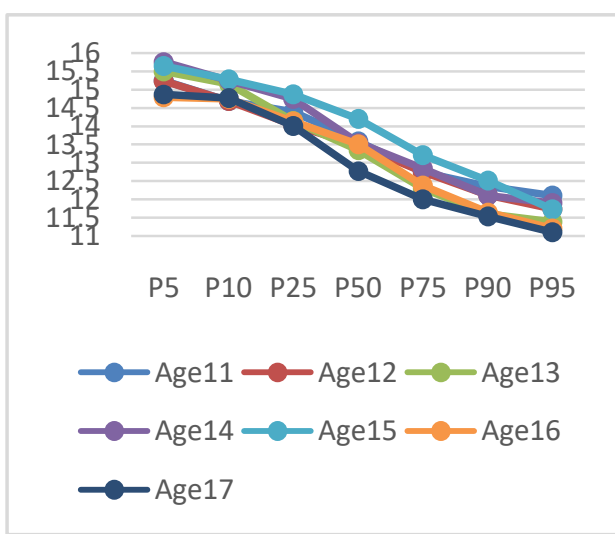

Figure 2: A Comparison of agility test norms of boys

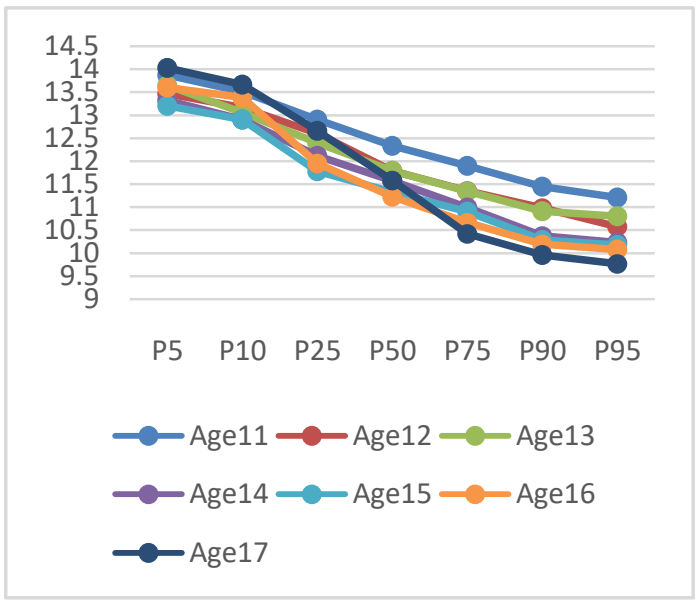

Figure 3: A Comparison of agility test norms of girls

Figure 2 and 3 revealed that P5 of the $4 \times 10 \mathrm{~m}$ shuttle run time of age 17 boys were very low comparing to other younger age groups. But at the end of the higher performance levels such as P75, P90 and P95, age 17 boys are performed better than their younger counterparts. This is an unusual pattern. Figure 2 shows the performance of girls of $4 \times 10$ mshuttle run which is indicate that there are clear differences between age groups. 
Age 11 girls perform at a low level of agility as the normal and it is increased up to age 17 category gradually. The lowest P5 of boy's $4 \times 10 \mathrm{~m}$ shuttle run test performance is 14 seconds and the highest P5 is 13.25 seconds. Meanwhile, lowest P95 of boy's 4x10m shuttle run test performance is $11.7 \mathrm{sec}$. and the highest P95 is 9.7 sec. According to the graph 43 the lowest P5 of girls' $4 \times 10 \mathrm{~m}$ shuttle run test performance is 15.7 sec. and the highest P5 is $14.7 \mathrm{sec}$. Furthermore, lowest P95 of girls' $4 \times 10 \mathrm{~m}$ shuttle run test performance is $12.3 \mathrm{sec}$. and the highest P95 is $11.3 \mathrm{sec}$.

\section{DISCUSSION}

Finding of this $4 \times 10 \mathrm{~m}$ references constructed the school children lives in the Kandy distract of Sri Lanka. The other limitation of this study is the sample size consisted of 1229 (both boys and Girls).Therefore, to established Sri Lanka National Norms the sample size is not enough and it need a large sample. The findings of this study differ with similar studies especially in European Union studies (Kolimechkov, S., Petrov, L., \& Alexandrova, A. (2019).

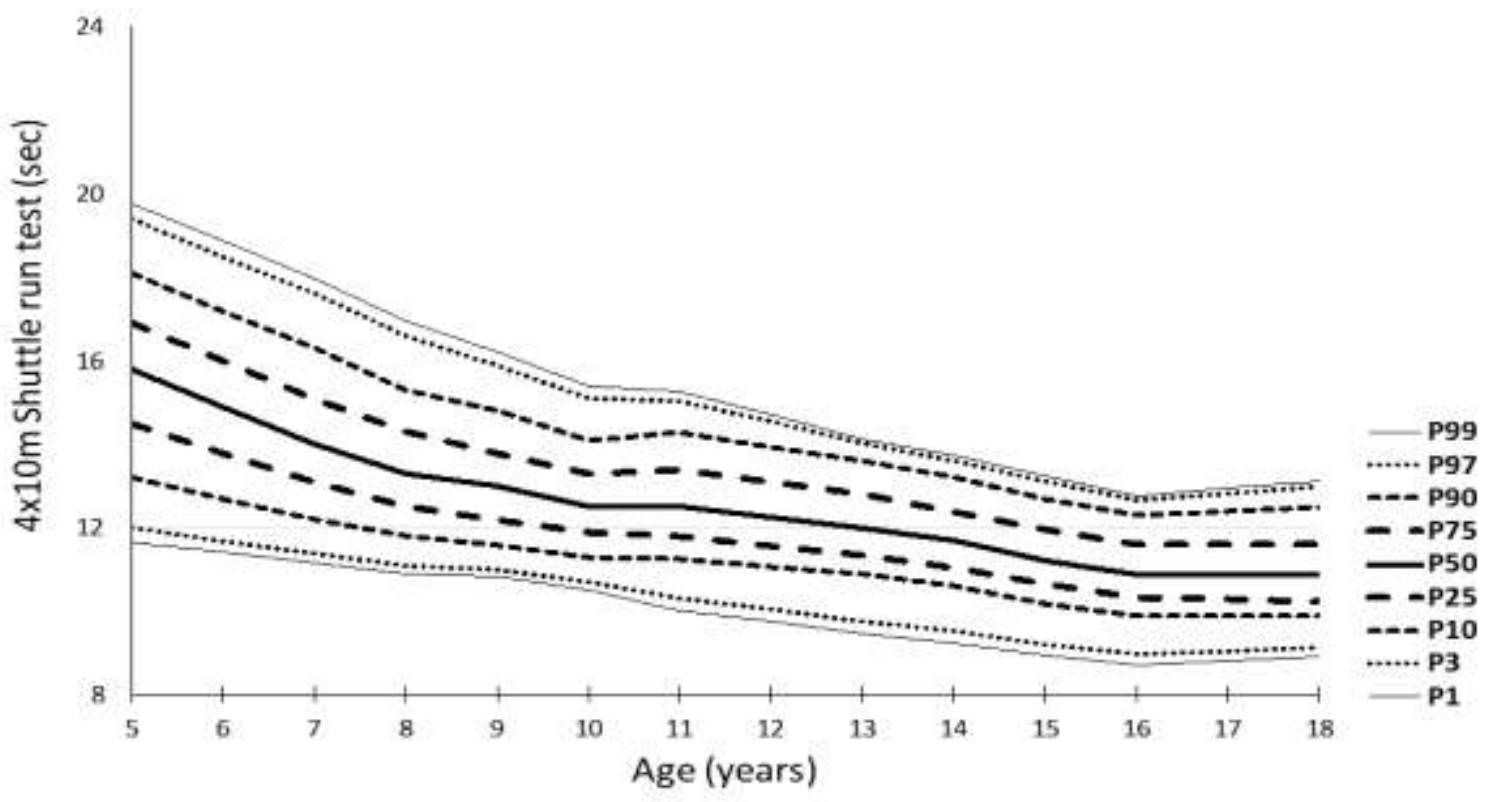

Figure 4: Alpha-fit test battery norms for children and adolescents from 5 to 18 years

According to the above figure 4 it can be identified the normative value deference between two studies .Meanwhile, $4 \times 10 \mathrm{~m}$ shuttle run is a valid and trustworthy measure, with the advantage of being used to evaluate a large number of participants simultaneously(Castro-Piñero J, Artero EG, España-Romero V, Ortega FB, Sjöström M, Suni J, et al. 2010).Another advantage is the motivational aspect, because it involves running activity, which is considered to be an attractive activity among children. In clinical practice, field tests are more viable because they do not require high cost equipment and are simpler to be applied, because tests performed on a treadmill, for instance, depend on the child's motor adaptation.

\section{V .CONCLUSION}

It can be concluded that although the agility levels of Sri Lankan children (both boys and girls) are not in the range of poor range. They are slightly different with the USA and European norms. However, we cannot say agility level of Sri Lankan boys and girls are not in a satisfactory level compared to such as USA standards, because these figures are normative base values. These norms are identical for some $\mathrm{sp}$ population. It can be recommended that agility fitness $\mathrm{c}$ objectively assessed by tests conducted in laboratory, but the need of expensive equipment limits its use in school environment. In this context, field tests might be an alternative for assessing agility fitness in school children, due to its low cost and its easy applicability, with the advantage that a big number of children can be assessed simultaneously.

\section{REFERENCES}

[1] Bouchard, C, \&Shephard, R1994, Physical activity, fitness and health: the model and key concepts. In: Bouchard C, Shephard R, Stephens $\mathrm{T}$ (Eds) Physical activity, fitness and health. International proceedings and consensus statement. Human Kinetics, Champaign, IL, pp. 77-88.

[2] Canadian Society for Exercise Physiology, (2003). Canadian physical activity, fitness and lifestyle approach (3rd Ed.). Ottowa: The Society.

[3] Caspersen, C.J., Powell, K.E., \& Christenson, G.M. (1985). Physical activity, exercise and physical fitness: Definitions and distinctions for health-related research. Public Health Reports, 100, pp. 126-130.

[4] Castro-Piñero J, Artero EG, España-Romero V, Ortega FB, Sjöström M, Suni J, et al. Criterion-related validity of field-based 
fitness tests in youth: A systematic review. Br J Sports Med. 2010;44(13):934-43.

[5] Danansuriya, M.J. et al (2013) Improving Adolescents Health in Sri Lanka .International Conference on Public Health Innovations , National Institute of Health Sciences, Sri Lanka

[6] Institute of Medicine. (2012).Fitness measures and health outcomes in youth. Washington, DC: The National Academies Press.

[7] Kolimechkov, S., Petrov, L., \& Alexandrova, A. (2019). Alpha-fit test battery norms for children and adolescents from 5 to 18 years of age obtained by a linear interpolation of existing European physical fitness references. European Journal of Physical Education and Sport Science, 5(4), 1-14.

[8] Kolimechkov, S. (2017). Physical Fitness Assessment in Children and Adolescents: A Systematic Review. European Journal of Physical Education and Sport Science, 3(4), 6578.https://www.stk-sport.co.uk/gymnastics-science-physicalfitness-norms.html

[9] Ortega, F.B., Silventoinen, K., Tynelius, P., \& Rasmussen, F. (2012). Muscular strength in male adolescents and premature death: cohort study of one million participants. British Medical Journal, 345, e7279.

[10] Thilakarathne, R.M.L.R., Wijesinghe, D.G.N.G. (2011). Association between

[11] Nutritional Status and Life Style Practices of Primary School Children in the

[12] Colombo District: A Pilot Study. Tropical Agricultural Research, 22, pp. 392-401.

[13] US Department of Health and Human Services. (1986). 1985 President's Council on Physical Fitness and Sports Youth Survey. Washington, DC: US Government Printing Office

[14] Welk G.J., Meredith, M. (Eds.) (2008). FITNESSGRAM® Reference Guide. Dallas, TX: The Cooper Institute. Available at: http://www.cooperinst.org/reference-guide Accessed 7/15/2013

[15] Wickramasinghe, V.P., Lamabadusuriya, S.P., Atapattu, N., Sathyadas, G., Karuparanantha, S., et al. (2004). Nutritional status of school children in an urban area of Sri Lanka. Ceylon Medical Journal 49, p.4.

https://www.stk-sport.co.uk/gymnastics-science-physical-fitnessnorms-4x10m-shuttle-run-test.html 